
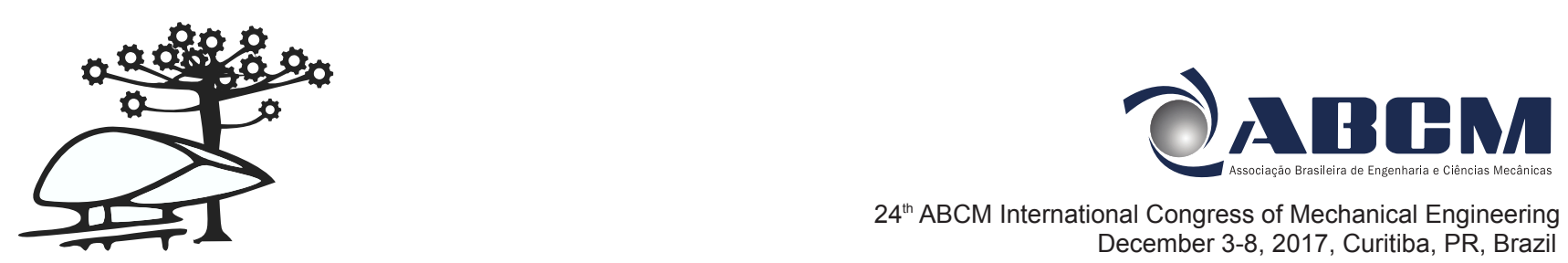

\title{
COBEM-2017-0618 \\ CARBON MONOXIDE COMBUSTION SIMULATIONS BY REDUCED MECHANISM
}

\section{Rafaela Sehnem}

Regis Sperotto de Quadros

Graduate Program in Mathematical Modelling, UFPel, Pelotas, Brazil

rafa-sehnem@hotmail.com and quadros99@gmail.com

\section{Alvaro Luiz de Bortoli}

Department of Pure and Applied Mathematics, UFRGS, Porto Alegre, Brazil

dbortoli@mat.ufrgs.br

Abstract. This paper presents the reactions and equations required for modelling the combustion mechanism of carbon monoxide. Some concepts of chemical kinetics are presented, such as reaction rates and steady-state and partial equilibrium approximations. Thereafter, the complete mechanism for combustion of $C O$ is displayed and a reduction of the mechanism is made to reduce the rigidity of the system. The resulting system of ordinary differential equations is integrated by the four-stage fourth-order L-stable Rosenbrock method. A simulation of the reduced mechanism is made assuming very small initial molar concentrations for the species, with the exception of the reagents.

Keywords: carbon monoxide; combustion; Rosenbrock method; stiff systems

\section{INTRODUCTION}

Concern about the emission of pollutants into the Earth's atmosphere has been increasing considerably. Air pollution is caused by natural or anthropogenic effects. While natural pollution remains constant, man-made pollution levels are steadily rising. One of the main pollutants is carbon monoxide, which already has established standards for air quality control.

Carbon monoxide is released into the environment by several sources. The natural sources can be: emission of natural gas, volcanic activity or electric discharges. Anthropogenic sources are equivalent to approximately $60 \%$ of the carbon monoxide present in the troposphere. This pollutant is a product of incomplete combustion (burning under low oxygen conditions of fuels such as firewood, charcoal, gasoline, kerosene, diesel), heating systems, biomass burning, among others.

In addition, the study of the combustion of carbon monoxide is essential for understanding this process in larger molecules of biofuels such as methanol and ethanol, since carbon monoxide is a by-product of the combustion of these species, as can be seen in Fig. 1, from Bortoli and Andreis (2012).

The computational simulations with detailed mechanisms turn complicated by the existence of highly reactive radicals which induces significant stiffness to the governing equations. Consequently, there exists the need to develop reduced mechanisms of fewer variables and moderate stiffness, while maintaining the accuracy of the detailed mechanism (Lu and Law, 2006).

Stiffness is defined as follows: "if a numerical method with a finite region of absolute stability, applied to a system with any initial conditions, is forced to use in a certain interval of integration a steplength which is excessively small in relation to the smoothness of the exact solution in that interval, then the system is said to be stiff in that interval" (Lambert, 1977).

This article is divided into four sections. The first, that ends here, presents the motivation of the combustion studies. In the following section are some concepts of chemical kinetics required for the modelling of combustion and also the mechanism for carbon monoxide combustion and its reduction. In the next section the numerical results of the simulation of the reduced mechanism are displayed and, finally, the obtained conclusions are presented.

\section{METHODOLOGY}

For a better understanding of the combustion process, it is necessary to construct the reaction mechanism that represents the burning of this fuel. In chemistry, a reaction mechanism is the step by step sequence of elementary reactions by 


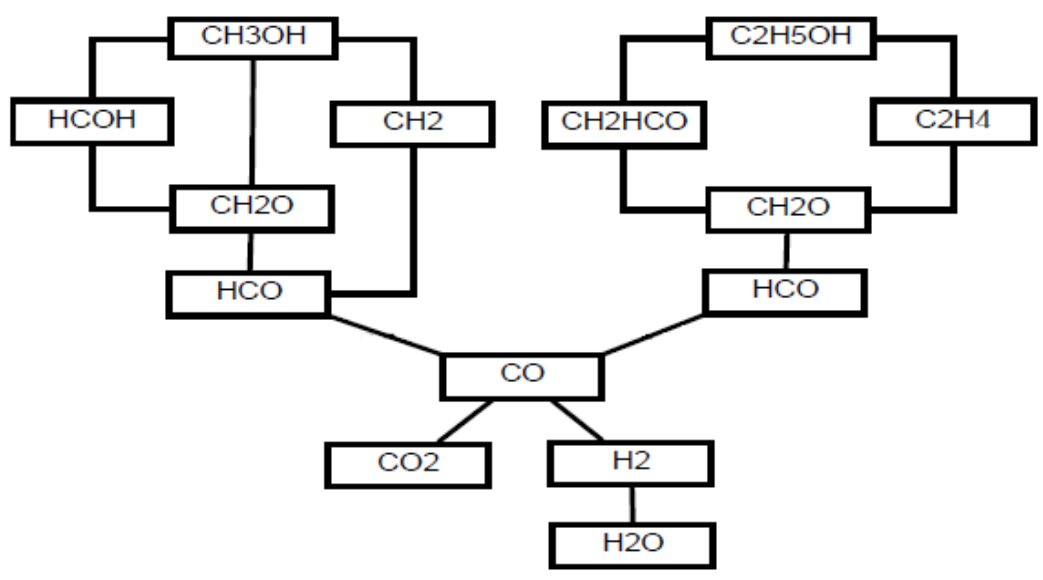

Figure 1. Diagram of the main chain for hydrogen, carbon monoxide, methanol and ethanol.

which overall reaction occurs. Some concepts of chemical kinetics are needed for modelling the mechanism.

When a molecule $A$ reacts with a molecule $B$ to form the molecules $C$ and $D$

$$
A+B \stackrel{k_{f}}{\longrightarrow} C+D
$$

species $A$ is consumed at the same rate as $B$. The rate of consumption of species $A$ is proportional to the molar concentrations of $A$ and $B$. Once $A$ is consumed the time derivative of its molar concentration is negative. Introducing $k_{f}$ as a constant of proportionality, it may be written as

$$
\left(\frac{d[A]}{d t}\right)_{f}=-k_{f}[A][B]=-\omega .
$$

The forward rate coefficient $k_{f}$ is, in principle, only a function of temperature $(T)$. Eq. (2) can be rewritten in order to suggest this dependence.

$$
-\frac{d[A]}{d t}=\left[\begin{array}{c}
\text { Number of collisions } \\
\text { between } \text { A and } B \text { molecules } \\
\text { Volume unit } \times \\
\text { Time Unit }
\end{array}\right] \cdot\left[\begin{array}{c}
\text { Probability that } a \\
\text { collision leads to } \\
\text { a reaction }
\end{array}\right] \cdot\left[\frac{\text { kmol of } A}{N \text { of molecules of } A}\right]
$$

or

$$
-\frac{d[A]}{d t}=\left(Z_{A B} / V\right) \cdot \mathcal{P} N_{A V}^{-1}
$$

where $N_{A V}$ is the Avogadro number.

The probability a collision can lead to a reaction can be expressed as a product of two factors: a factor of energy, $e^{-E_{A} / R_{u} T}$, which expresses the fraction of collisions that occurs with an energy above the level necessary for the reaction - $E_{A}$, or activation energy; and a geometric or steric factor, $p$, which takes into account the geometry of collision between $A$ and $B$. For example, in the reaction between $\mathrm{OH}$ and $\mathrm{H}$ to form $\mathrm{H}_{2} \mathrm{O}$, intuitively one expects that there will be reaction if the hydrogen atom collides with the $O$ side of the hydroxyl, instead of the $H$ side, since the product has bonds of the form $H-O-H$. In general, steric factor values are much less than one, but there are exceptions.

Thus, Eq. 4 becomes

$$
-\frac{d[A]}{d t}=p N_{A V} \sigma_{A B}^{2}\left[\frac{8 \pi k_{B} T}{\mu}\right]^{1 / 2} \cdot e^{\left(-E_{A} / R_{u} T\right)}[A][B],
$$

where the substitutions $n_{A} / V=[A] N_{A V}$ and $n_{B} / V=[B] N_{A V}$ were employed and $k_{B}$ is the Boltzmann constant. Comparing Eq. (2) and (5), note that the bimolecular rate coefficient, based on the theory of collisions, is

$$
k(T)=p N_{A V} \sigma_{A B}^{2}\left[\frac{8 \pi k_{B} T}{\mu}\right]^{1 / 2} \cdot e^{\left(-E_{A} / R_{u} T\right)} .
$$


If the temperature range of interest is not very wide, the bimolecular rate coefficient can be expressed by the empirical Arrhenius form,

$$
k(T)=B \cdot e^{\left(-E_{A} / R_{u} T\right)},
$$

where $A$ is a constant called pre-exponential or frequency factor. Comparing equations (6) and (7), we see that $A$ is not a constant but depends, based on collision theory, on $T^{1 / 2}$. Arrhenius plots of $\log k$ and $1 / T$ for experimental data are used to obtain activation energy values, since the slope of such plots is $-E_{A} / R_{u}$.

Even if the tabulation of experimental values for rate coefficients in Arrhenius form is common, the most frequent practice is to use the form with three parameters:

$$
k(T)=A T^{\beta} \cdot e^{\left(-E_{A} / R_{u} T\right)},
$$

where $A, \beta$ and $E_{A}$ are empirical parameters.

The mechanism for the combustion of carbon monoxide is composed of 26 reactions and 11 species, presented by Marinov (1999), according to the Tab. 1. The modelling of this mechanism implies a system of 11 nonlinear ordinary differential equations with a very high degree of stiffness, which makes analytical and numerical resolution difficult.

\begin{tabular}{|c|c|c|c|}
\hline Reaction & $A$ & $\beta$ & $E_{A}$ \\
\hline 1. $\mathrm{OH}+\mathrm{H}_{2}=\mathrm{H}+\mathrm{H}_{2} \mathrm{O}$ & $2.14 E+08$ & 1.52 & 3449 \\
\hline 1b. $\mathrm{H}+\mathrm{H}_{2} \mathrm{O}=\mathrm{OH}+\mathrm{H}_{2}$ & $5.09 E+09$ & 1.30 & 18588 \\
\hline 2. $\mathrm{O}+\mathrm{OH}=\mathrm{O}_{2}+\mathrm{H}$ & $2.02 E+14$ & -0.40 & 0 \\
\hline 3. $\mathrm{O}+\mathrm{H}_{2}=\mathrm{OH}+\mathrm{H}$ & $5.06 E+04$ & 2.67 & 6290 \\
\hline 4. $\mathrm{H}+\mathrm{O}_{2}+\mathrm{M}=\mathrm{HO}_{2}+\mathrm{M}$ & $4.52 E+13$ & 0.00 & 0 \\
\hline 5. $\mathrm{OH}+\mathrm{HO}_{2}=\mathrm{H}_{2} \mathrm{O}+\mathrm{O}_{2}$ & $2.13 E+28$ & -4.83 & 3500 \\
\hline 6. $\mathrm{H}+\mathrm{HO}_{2}=\mathrm{OH}+\mathrm{OH}$ & $1.50 E+14$ & 0.00 & 1000 \\
\hline 7. $\mathrm{H}+\mathrm{HO}_{2}=\mathrm{H}_{2}+\mathrm{O}_{2}$ & $6.63 E+13$ & 0.00 & 2126 \\
\hline 8. $\mathrm{H}+\mathrm{HO}_{2}=\mathrm{O}+\mathrm{H}_{2} \mathrm{O}$ & $3.01 E+13$ & 0.00 & 1721 \\
\hline 9. $\mathrm{O}+\mathrm{HO}_{2}=\mathrm{O}_{2}+\mathrm{OH}$ & $3.25 E+13$ & 0.00 & 0 \\
\hline 10. $2 \mathrm{OH}=\mathrm{O}+\mathrm{H}_{2} \mathrm{O}$ & $3.57 E+04$ & 2.40 & -2112 \\
\hline 11. $H+H+M=H_{2}+M$ & $1.00 E+18$ & -1.00 & 0 \\
\hline 12. $\mathrm{H}+\mathrm{OH}+\mathrm{M}=\mathrm{H}_{2} \mathrm{O}+\mathrm{M}$ & $2.21 E+22$ & -2.00 & 0 \\
\hline 13. $H+O+M=O H+M$ & $4.71 E+18$ & -1.00 & 0 \\
\hline 14. $O+O+M=O_{2}+M$ & $1.89 E+13$ & 0.00 & -1788 \\
\hline 15. $\mathrm{HO}_{2}+\mathrm{HO}_{2}=\mathrm{H}_{2} \mathrm{O}_{2}+\mathrm{O}_{2}$ & $4.20 E+14$ & 0.00 & 11982 \\
\hline 16. $\mathrm{OH}+\mathrm{OH}+\mathrm{M}=\mathrm{H}_{2} \mathrm{O}_{2}+\mathrm{M}$ & $1.24 E+14$ & -0.37 & 0 \\
\hline 17. $\mathrm{H}_{2} \mathrm{O}_{2}+\mathrm{H}=\mathrm{HO}_{2}+\mathrm{H}_{2}$ & $1.98 E+06$ & 2.00 & 2435 \\
\hline 18. $\mathrm{H}_{2} \mathrm{O}_{2}+\mathrm{H}=\mathrm{OH}+\mathrm{H}_{2} \mathrm{O}$ & $3.07 E+13$ & 0.00 & 4217 \\
\hline 19. $\mathrm{H}_{2} \mathrm{O}_{2}+\mathrm{O}=\mathrm{OH}+\mathrm{HO}_{2}$ & $9.55 E+06$ & 2.00 & 3970 \\
\hline 20. $\mathrm{H}_{2} \mathrm{O}_{2}+\mathrm{OH}=\mathrm{H}_{2} \mathrm{O}+\mathrm{HO}_{2}$ & $2.40 E+00$ & 4.04 & -2162 \\
\hline 111. $\mathrm{HCO}+\mathrm{O}_{2}=\mathrm{HO}_{2}+\mathrm{CO}$ & $7.58 E+12$ & 0.00 & 410 \\
\hline 112. $H C O+M=H+C O+M$ & $1.86 E+17$ & -1.00 & 17000 \\
\hline 113. $\mathrm{HCO}+\mathrm{OH}=\mathrm{H}_{2} \mathrm{O}+\mathrm{CO}$ & $1.00 E+14$ & 0.00 & 0 \\
\hline 114. $\mathrm{HCO}+\mathrm{H}=\mathrm{CO}+\mathrm{H}_{2}$ & $1.19 E+13$ & 0.25 & 0 \\
\hline 126. $\mathrm{CO}+\mathrm{OH}=\mathrm{CO}_{2}+\mathrm{H}$ & $9.42 E+03$ & 2.25 & -2351 \\
\hline
\end{tabular}

Table 1. Carbon monoxide mechanism rate coefficients (units are $\mathrm{mol}, \mathrm{cm}^{3}, \mathrm{~s}, \mathrm{~K}$ and $\mathrm{cal} / \mathrm{mol}$ ).

(1) at $800 K$

For the set of equations presented in Tab. 1, the balance equations for the complete mechanism of carbon monoxide, 
where $\omega_{i}$ represents the reaction rate of the reaction $i$, are:

$$
\begin{aligned}
\frac{d\left[H_{2}\right]}{d t}= & -\omega_{1}+\omega_{1 b}-\omega_{3}+\omega_{7}+\omega_{11}+\omega_{17}+\omega_{114}, \\
\frac{d[H]}{d t}= & +\omega_{1}-\omega_{1 b}+\omega_{2}+\omega_{3}-\omega_{4}-\omega_{6}-\omega_{7}-\omega_{8}-2 \omega_{11}-\omega_{12}-\omega_{13}-\omega_{17} \\
& -\omega_{18}+\omega_{112}-\omega_{114}+\omega_{126}, \\
\frac{d\left[O_{2}\right]}{d t}= & +\omega_{2}-\omega_{4}+\omega_{5}+\omega_{7}+\omega_{9}+\omega_{14}+\omega_{15}-\omega_{111}, \\
\frac{d[O]}{d t}= & -\omega_{2}-\omega_{3}+\omega_{8}-\omega_{9}+\omega_{10}-\omega_{13}-2 \omega_{14}-\omega_{19}, \\
\frac{d\left[H_{2} O\right]}{d t}= & +\omega_{1}-\omega_{1 b}+\omega_{5}+\omega_{8}+\omega_{10}+\omega_{12}+\omega_{18}+\omega_{20}+\omega_{113}, \\
\frac{d[O H]}{d t}= & -\omega_{1}+\omega_{1 b}-\omega_{2}+\omega_{3}-\omega_{5}+2 \omega_{6}+\omega_{9}-2 \omega_{10}-\omega_{12}+\omega_{13}-2 \omega_{16} \\
& +\omega_{18}+\omega_{19}-\omega_{20}-\omega_{113}-\omega_{126}, \\
\frac{d\left[H O_{2}\right]}{d t}= & +\omega_{4}-\omega_{5}-\omega_{6}-\omega_{7}-\omega_{8}-\omega_{9}-2 \omega_{15}+\omega_{17}+\omega_{19}+\omega_{20}+\omega_{111}, \\
\frac{d\left[H_{2} O_{2}\right]}{d t}= & +\omega_{15}+\omega_{16}-\omega_{17}-\omega_{18}-\omega_{19}-\omega_{20}, \\
\frac{d[C O]}{d t}= & +\omega_{111}+\omega_{112}+\omega_{113}+\omega_{114}-\omega_{126}, \\
\frac{d\left[C O O_{2}\right]}{d t}= & +\omega_{126}, \\
\frac{d[H C O]}{d t}= & -\omega_{111}-\omega_{112}-\omega_{113}-\omega_{114} \cdot
\end{aligned}
$$

In order to simplify the chemical kinetics involved and favor the resolution of the problem, a reduction of the mechanism is made using some approximations, such as steady-state approximation and partial equilibrium. The steady-state hypothesis is valid for intermediate species that are produced by slow reactions and consumed by fast reactions, so their concentrations remain small (Turns, 2000). The hypothesis of partial equilibrium is justified when the velocities of the forward and backward reactions are much greater than the other specific velocities of the mechanism (Peters, 1988).

The result of assuming both the partial equilibrium and the steady-state approximation is similar: a concentration is determined by an algebraic equation rather than by integration of an ordinary differential equation. There are, however, differences between the two approximations. While the partial equilibrium forces a reaction - or a set of reactions - to be equilibrated, the steady-state approximation forces the rate of one or more species to be zero.

After applying the hypothesis of partial equilibrium for those reactions with high specific forward and backward velocities, it remains the reactions $1,3,11,12,13,14$ and 126 . Considering the steady-state hypothesis for the species $O H$, it results the following three-step mechanism among six species for carbon monoxide

$$
\begin{aligned}
I^{\prime} & \mathrm{CO}+\mathrm{H}_{2} \mathrm{O}=\mathrm{CO}_{2}+\mathrm{H}_{2} \\
I I^{\prime} & 3 \mathrm{H}_{2}+\mathrm{O}_{2}=2 \mathrm{H}+2 \mathrm{H}_{2} \mathrm{O} \\
I I I^{\prime} & \mathrm{H}+\mathrm{H}+\mathrm{M}=\mathrm{H}_{2}+M
\end{aligned}
$$

where $M$ is an inert needed to remove the bond energy that is liberated during recombination (Peters, 1992).

In this mechanism, the step $I^{\prime}$ is the overall $C O$ consumption step, which neither creates nor destroys reaction intermediaries. The step $I I^{\prime}$ represents an overall recombination step, and the step $I I I^{\prime}$ an overall radical production, oxygen-consumption step. The reactions $I I^{\prime}$ and $I I I^{\prime}$ constitute the two-step mechanism for the hydrogen.

The reduced mechanism obtained for carbon monoxide can be justified by asymptotic analysis. Assuming the steadystate hypothesis for $\mathrm{O}, \mathrm{OH}, \mathrm{HO}_{2}, \mathrm{H}_{2} \mathrm{O}_{2}$ and $\mathrm{HCO}$, their differential operators are set equal to zero, which leads to five algebraic equations among the reaction rates.

$$
\begin{aligned}
\omega_{13}= & -\omega_{2}-\omega_{3}+\omega_{8}-\omega_{9}+\omega_{10}-2 \omega_{14}-\omega_{19}, \\
\omega_{20}= & +\omega_{15}+\omega_{16}-\omega_{17}-\omega_{18}-\omega_{19} . \\
\omega_{6}= & +\omega_{4}-\omega_{5}-\omega_{7}-\omega_{8}-\omega_{9}-\omega_{15}+\omega_{16}-\omega_{18}+\omega_{111}, \\
\omega_{12}= & -\omega_{1}+\omega_{1 b}-2 \omega_{2}+2 \omega_{4}-3 \omega_{5}-2 \omega_{7}-\omega_{8}-2 \omega_{9}-\omega_{10}-2 \omega_{14}-3 \omega_{15} \\
& -\omega_{16}+\omega_{17}+\omega_{19}+2 \omega_{111}-\omega_{126} .
\end{aligned}
$$




$$
\omega_{113}=-\omega_{111}-\omega_{112}-\omega_{114}
$$

Making $\omega_{I^{\prime}}, \omega_{I I^{\prime}}$ and $\omega_{I I I^{\prime}}$ equal to

$$
\begin{aligned}
\omega_{I^{\prime}}= & \omega_{126}, \\
\omega_{I I^{\prime}}= & -\omega_{2}+\omega_{4}-\omega_{5}-\omega_{7}-\omega_{9}-\omega_{14}-\omega_{15}+\omega_{111}, \\
\omega_{I I I^{\prime}}= & -\omega_{1}+\omega_{1 b}-3 \omega_{2}-\omega_{3}+3 \omega_{4}-3 \omega_{5}-2 \omega_{7}-3 \omega_{9}+\omega_{11}-3 \omega_{14} \\
& -3 \omega_{15}+\omega_{17}+3 \omega_{111}+\omega_{114}-\omega_{126},
\end{aligned}
$$

the following linear combinations are obtained

$$
\begin{aligned}
\frac{d\left[H_{2}\right]}{d t} & =+\omega_{I^{\prime}}-3 \omega_{I I^{\prime}}+\omega_{I I I^{\prime}}, \\
\frac{d[H]}{d t} & =2 \omega_{I I^{\prime}}-2 \omega_{I I I^{\prime}}, \\
\frac{d\left[O_{2}\right]}{d t} & =-\omega_{I I^{\prime}}, \\
\frac{d\left[H_{2} O\right]}{d t} & =-\omega_{I^{\prime}}+2 \omega_{I I^{\prime}}, \\
\frac{d[C O]}{d t} & =-\omega_{I^{\prime}}, \\
\frac{d\left[C O_{2}\right]}{d t} & =+\omega_{I^{\prime}} .
\end{aligned}
$$

The stoichiometry of these balance equations corresponds to the following global mechanism of three-step for the carbon monoxide.

$$
\begin{aligned}
I^{\prime} & \mathrm{CO}+\mathrm{H}_{2} \mathrm{O}=\mathrm{CO}_{2}+\mathrm{H}_{2} \\
I I^{\prime} & 3 \mathrm{H}_{2}+\mathrm{O}_{2}=2 \mathrm{H}+2 \mathrm{H}_{2} \mathrm{O} \\
I I I^{\prime} & \mathrm{H}+\mathrm{H}+\mathrm{M}=\mathrm{H}_{2}+M
\end{aligned}
$$

Consequently, the complete mechanism with 26 reactions and 11 species was reduced to a mechanism with 3 reactions and 6 species, which has a moderate degree of stiffness.

\section{NUMERICAL RESULTS}

In order to simulate the reduced mechanism for carbon monoxide combustion, the fourth-order Rosenbrock method with four stages was chosen with a formula for adaptive control for the integration step. This method is L-stable, which is ideal for solving stiff systems, since they have maximally damped behavior. The fourth-order four-stage Rosenbrock method is given by:

$$
\begin{aligned}
& y_{n+1}=y_{n}+h \sum_{i=1}^{4} \gamma_{i} \kappa_{i} \\
& \kappa_{1}=f\left(y_{n}\right) / A\left(y_{n}\right) \\
& \kappa_{2}=f\left(y_{n}+h a_{21} \kappa_{1}\right) / A\left(y_{n}\right) \\
& \kappa_{3}=f\left(y_{n}+h\left(a_{31} \kappa_{1}+a_{32} \kappa_{2}\right)\right) / A\left(y_{n}\right) \\
& \kappa_{4}=f\left(y_{n}+h\left(a_{41} \kappa_{1}+a_{42} \kappa_{2}+a_{43} \kappa_{3}\right)\right) / A\left(y_{n}\right)
\end{aligned}
$$

where

$$
A\left(y_{n}\right)=\left[I-h d \frac{\partial f\left(y_{n}\right)}{\partial y}\right]
$$

The local error estimation is calculated by

$$
E_{n+1}=\frac{\left\|y_{n+1}^{*}-y_{n+1}\right\|}{\left(2^{\rho}-1\right)}
$$


considering the norm $\|\cdot\|$ as

$$
\|y\|=\left[\frac{1}{\phi} \sum_{i=1}^{\phi}\left(\frac{y_{n+1}^{i}}{y_{\max }^{i}}\right)^{2}\right]^{1 / 2}
$$

Taking into account a tolerance $\varepsilon$, one can choose the procedure below to determine the time increment (Bui and Bui, 1979):

- If $E_{n+1}>\varepsilon$, the increment is rejected and $h$ should be reduced.

- If $\frac{3 \varepsilon}{4}<E_{n+1}<\varepsilon$, the increment is accepted, but $h$ should be reduced.

- If $\frac{\varepsilon}{10}<E_{n+1}<\frac{3 \varepsilon}{4}$, the increment is accepted and $h$ should be sustained.

- If $E_{n+1}<\frac{\varepsilon}{10}$ the increment is accepted and $h$ can be increased.

The variables $y_{n+1}^{*}$ and $y_{n+1}$ are calculated using the step of time $h$ and $h / 2$, respectively. To avoid divergence during the iterative process the increment for the step needs to be limited, which can be done by the following equation, agreeing with Bortoli et al. (2015):

$$
h_{n+1}=h_{n} \min \left[10, \max \left(0,1 ; \frac{0,9}{\Delta y}\right)^{2}\right] \text {. }
$$

It is also necessary that the values of the step-size be limited by maximum and minimum values, the initial time increment must be small enough and, in case of $h_{n+1}$ rejection, the growth factor should be replaced by 1 , instead of 10 , in the next iteration.

For the resolution of the linear system of each stage in each iteration the successive sub-relaxation method (SUR) was used. The SUR method is given by

$$
y^{[n]}=(1-\delta) y^{[n-1]}+\frac{\delta}{s_{i i}}\left(b_{i}-\sum_{j=1}^{i-1} s_{i j} y_{j}^{[n]}-\sum_{j=i+1}^{N} s_{i j} y_{j}^{[n-1]}\right), i=1, \ldots, N \text { and } n=0,1,2, \ldots
$$

The code was implemented in the Fortran 90 language using double precision and a tolerance for error $\varepsilon=10^{-7}$. It took about 6000 iterations to achieve chemical equilibrium. Molar concentrations over the integration interval can be seen in Fig. 2 and Tab. 2. The local error is in Fig. 3.

At the beginning of the process (up to time $10^{-4}$ ) the main reaction is the $I^{\prime}$. From the moment there is a higher concentration of $\mathrm{H}_{2}$, reactions $I I^{\prime}$ and $I I I^{\prime}$ stand out and water is produced again. At the moment the carbon monoxide is fully consumed, the $\mathrm{CO}_{2}$ concentration stabilizes.

Table 2. Molar concentrations $\left(\mathrm{mol} / \mathrm{cm}^{3}\right)$ obtained in the integration of the $C O$ combustion reduced mechanism.

\begin{tabular}{|c|c|c|c|c|c|c|}
\hline Time $(\mathrm{s})$ & $\mathrm{H}_{2}$ & $\mathrm{O}_{2}$ & $\mathrm{H}$ & $\mathrm{H}_{2} \mathrm{O}$ & $\mathrm{CO}$ & $\mathrm{CO}_{2}$ \\
\hline $1 \times 10^{-6}$ & $2,931 \times 10^{-4}$ & 0,022 & $9,993 \times 10^{-6}$ & 0,06972 & 0,04972 & 0,00128 \\
\hline $1 \times 10^{-5}$ & 0,0024 & 0,022 & $9,956 \times 10^{-6}$ & 0,06761 & 0,04761 & 0,00339 \\
\hline $1 \times 10^{-4}$ & 0,01719 & 0,02196 & $8,049 \times 10^{-5}$ & 0,05278 & 0,0327 & 0,0183 \\
\hline $1 \times 10^{-3}$ & 0,03371 & 0,01547 & $4,757 \times 10^{-4}$ & 0,03607 & 0,00302 & 0,04798 \\
\hline $1 \times 10^{-2}$ & 0,01629 & 0,00517 & $9,220 \times 10^{-5}$ & 0,05367 & $5,760 \times 10^{-17}$ & 0,051 \\
\hline $1 \times 10^{-1}$ & 0,0087 & 0,00136 & $1,839 \times 10^{-5}$ & 0,06129 & $1 \times 10^{-60}$ & 0,051 \\
\hline 1 & 0,00612 & $6,261 \times 10^{-5}$ & $2,332 \times 10^{-6}$ & 0,06387 & $1 \times 10^{-60}$ & 0,051 \\
\hline
\end{tabular}

\section{CONCLUSIONS}

In a growing area of study, where computational models have codes that become more complex with each advancement, finding simplifications that facilitate analysis and reduce computational expenditure is essential. In this way, the simplifications used in this work contribute to the achievement of good results, with reduced stiffness of the system. The main advantage of the reduction of the mechanism is the decrease of the work required to solve the system of equations. The time required for the resolution of chemical equations reduces by an order of magnitude for carbon monoxide, since the number of equations decreases in that order. For the continuity of this work, it is intended to simulate reduced mechanisms of larger molecules of biofuels, such as methanol and ethanol, for example. 


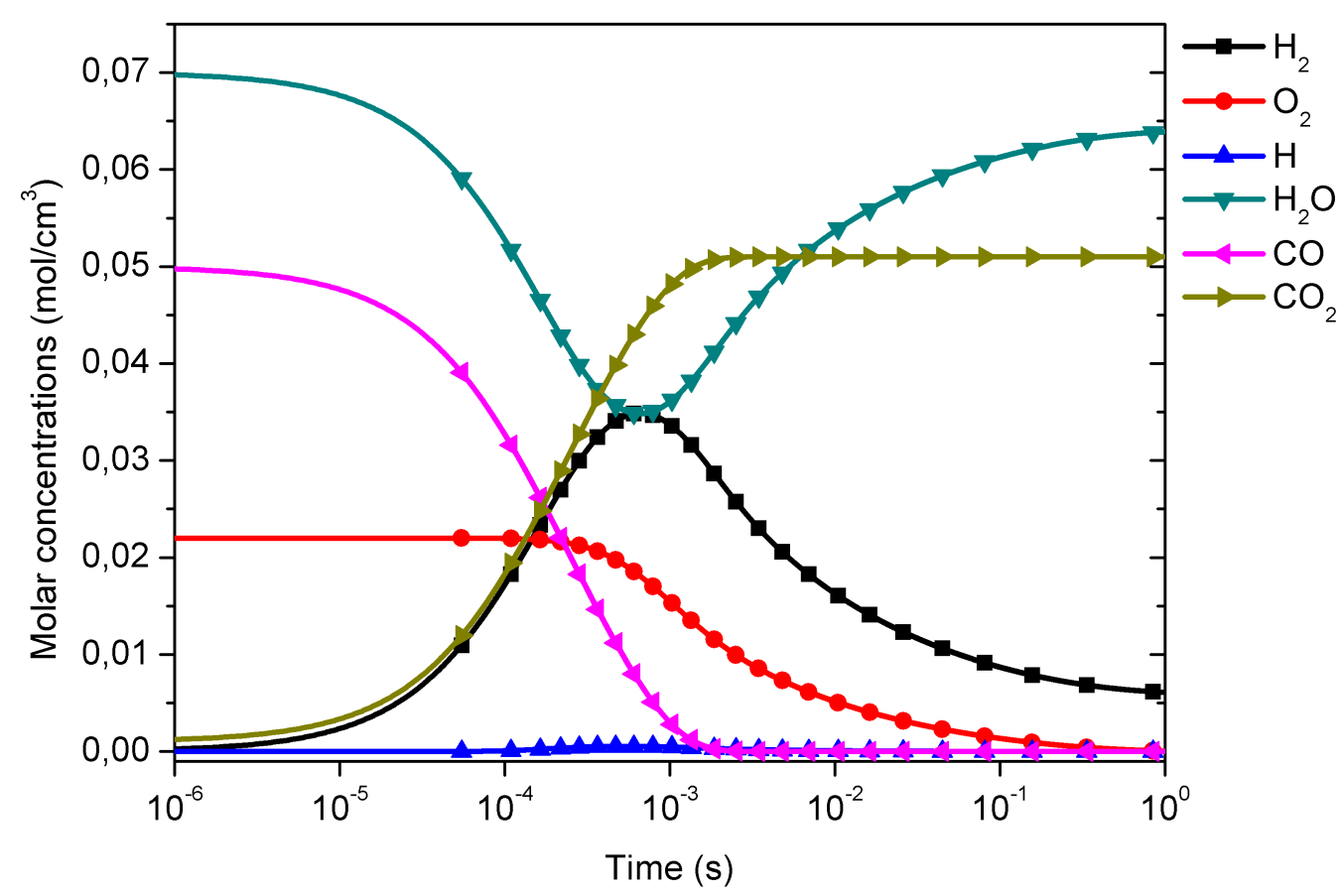

Figure 2. Simulation of carbon monoxide reduced mechanism.

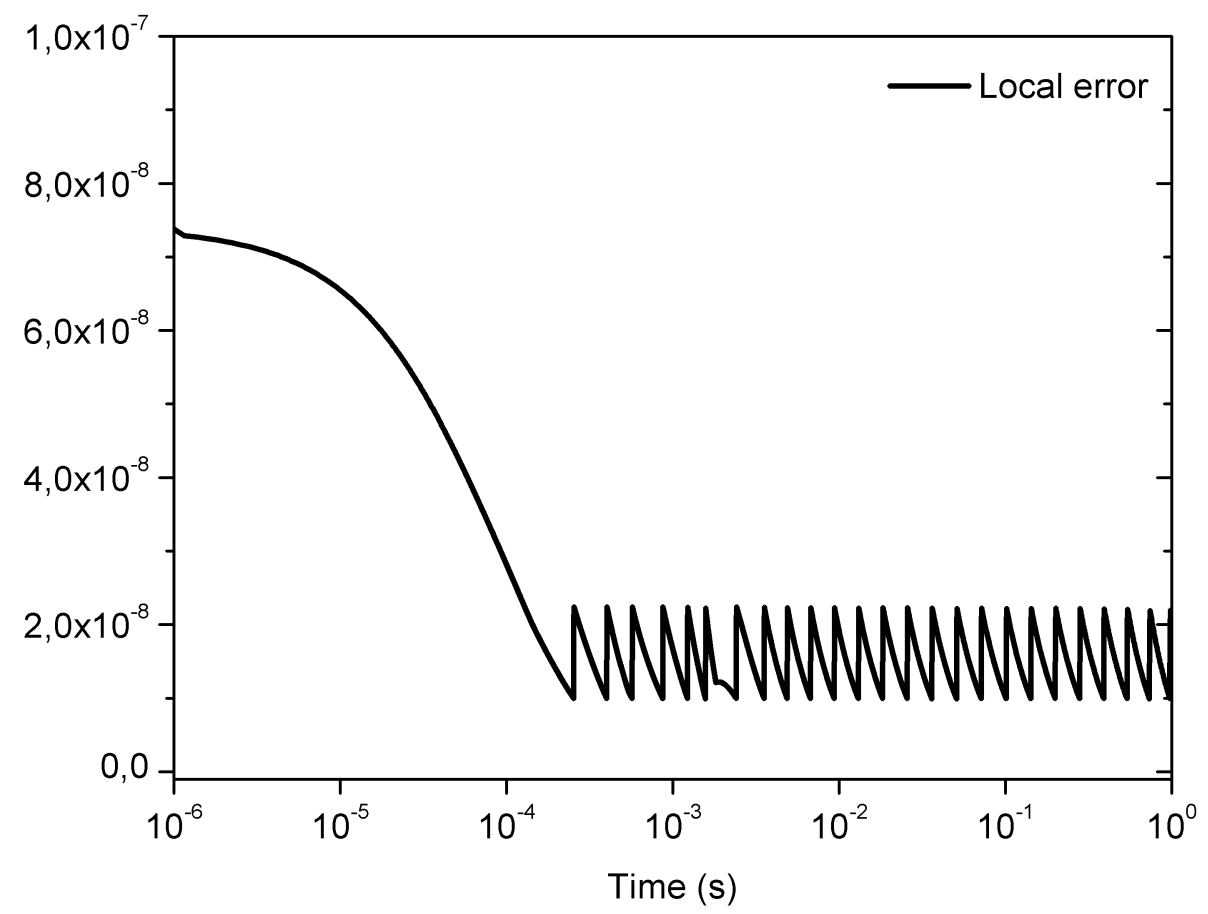

Figure 3. Local error with tolerance $\varepsilon=10^{-7}$.

\section{ACKNOWLEDGMENTS}

This work was supported by CAPES - Coordination of Superior Level Staff Improvement. 


\section{REFERENCES}

Bortoli, A.L.D. and Andreis, G.S.L., 2012. "Asymptotic analysis for coupled hydrogen, carbon monoxide, methanol and ethanol reduced kinetic mechanisms". Latin American Applied Research, Vol. 42, p. 299.

Bortoli, A.L.D., Andreis, G.S.L. and Pereira, F.N., 2015. Modeling and Simulation of Reactive Flows. Elsevier, Amsterdam, 1 st edition.

Bui, T.D. and Bui, T.R., 1979. "Numerical methods for extremely stiff systems of ordinary differential equations". Applied Mathematical Modelling, Vol. 3, p. 355.

Lambert, J.D., 1977. "The initial value problem for ordinary differential equations".

Lu, T. and Law, C.K., 2006. "Linear time reduction of large kinetic mechanisms with directed relation graph: n-heptane and iso-octane". Combustion and Flame, Vol. 144, No. 1, pp. 24-36.

Marinov, N.M., 1999. “A detailed chemical kinetic model for high temperature ethanol oxidation”. International Journal of Chemical Kinetics, Vol. 31, p. 183.

Peters, N., 1988. "Systematic reduction of flame kinetics- principles and details". Dynamics of reactive systems. Part 1: Flames, Vol. 1, p. 67.

Peters, N., 1992. "Fifteen lectures on laminar and turbulent combustion". Ercoftac Summer School, Vol. 1428, p. 245.

Turns, S.R., 2000. An introduction to combustion. Boston: M cGraw Hill, New Delhi, 2nd edition.

\section{RESPONSIBILITY NOTICE}

The authors are the only responsible for the printed material included in this paper. 